\title{
Distribution of forest ecosystems over two centuries in a highly urbanized landscape
}

Robert T. FAHEY - Corresponding author

Department of Natural Resources and the Environment \& Center for Environmental Sciences

and Engineering, University of Connecticut, 1376 Storrs Rd. Unit 4087, Storrs, CT, 06269, USA, Email: Robert.fahey@uconn.edu,Phone: (860) 486-0148

\section{Matthew CASALI}

Center for Tree Science, The Morton Arboretum, Email: mattcasali1 @ gmail.com 


\section{Abstract}

2 Urban development often results in diminished forest cover and severely fragmented landscapes,

3 but most research on effects of urban development has been focused on densely forested regions

4 and has not distinguished remnant from recently established forest cover. Urban development

5 may have different effects in heterogeneous landscapes with high pre-urban fragmentation. Our

6 study investigated spatial and temporal distribution of remnant forest ecosystems across a large

7 urban landscape to assess effects of landscape structure and development patterns on forest

8 conversion. Forest ecosystem distribution within the greater Chicago region $\left(18,822 \mathrm{~km}^{2}\right)$ was

9 mapped in three time periods using Public Land Survey records (1830's) and aerial imagery

10 (1939 and 2010). Loss of original forest between sampling periods (conversion) was related to

11 landscape features, land use, and sociodemographic factors. In $2010 \sim 17 \%$ of pre-urban forest

12 area remained, which represented $\sim 40 \%$ reduction relative to 1939 . Conversion did not differ

13 greatly with urbanization, but fragmentation was greater in areas with high population density

14 and rapid population growth. Conversion was lower in areas close to waterways, where there was

15 less impervious surface, and also differed among land uses (highest in agricultural and

16 industrial). Remnant forests had higher canopy cover, basal area, and native species dominance

17 than recently established forests. Urbanization may have lower relative effects on total forest

18 cover in naturally fragmented landscapes, but may result in extreme fragmentation. Remnant

19 forests had characteristics consistent with high functional value, but creating connectivity among

20 ecosystems in highly urbanized areas will require promotion of canopy cover in urban land uses.

21

22 Keywords: fragmentation; urban development; remnant forest; aerial image analysis; Quercus;

23 Chicago 


\section{Introduction}

Development in urban regions can have deleterious effects on forest cover and connectivity (Medley et al., 1995; Nowak \& Walton, 2005; Riitters et al., 2002), but spatial and temporal patterns of canopy loss within these landscapes can be complex (Sanders, 1984). Intense development in the urban core can lead to extreme loss of canopy cover, although recent urban tree planting may ameliorate this effect to some degree (Zhou et al., 2011). In densely forested regions, this conversion can result in landscapes with strong urban-rural differences in canopy cover and habitat connectivity (Miller, 2012). This is especially true in areas where rural canopy cover has recently increased due to regrowth of forest cover related to agricultural abandonment (Zhou et al., 2011). More recent suburban and exurban development has led to increasing fragmentation of forest cover relative to pre-urban conditions in areas beyond the urban core (Radeloff et al., 2005). Such development may decrease differences in canopy cover between core and rural areas, but these differences likely persist in most densely forested regions (Miller, 2012; Zhou et al., 2011).

Much of the research on the effects of urbanization on forests has been conducted in densely forested regions, but many urban areas are situated in landscapes that were either unforested or had a heterogeneous landscape composed of a variety of ecosystem types prior to urbanization (Nowak et al., 1996; Schleeweis et al., 2013). At the sparsely forested end of this spectrum are biophysical regions such as plains or deserts, where the pattern of tree canopy cover in the urban landscape is essentially the opposite of that in densely forested regions, with greater canopy cover in more urbanized parts of the landscape due to tree planting and water diversion (Nowak et al., 1996). However, intermediate on this spectrum are more heterogeneous, partially-forested landscapes, where the effect of urban development on canopy cover and habitat connectivity 
47 relative to the original landscape condition may be less straightforward and uncertain (Bigsby et 48 al., 2014; Gillespie et al., 2012).

49 An example of a region where forested ecosystems were patchily distributed and thus 50 relatively fragmented prior to urban development is the central part of North America, which 51 historically consisted of a mixture of prairie and forest ecosystems (Anderson, 1991; Bowles et 52 al., 1994). Modern patterns of forest cover in metropolitan areas in this region have been shaped 53 by this landscape legacy as well as development patterns (Fahey et al., 2012; Iverson \& Cook, 54 2000; Sharpe et al., 1986; Ward et al., 2007). In Midwestern US cities such as Chicago, modern 55 forest cover is strongly concentrated in protected reserves in parks and other natural areas, which 56 are more prevalent in areas closer to the urban core than in the exurban and highly agricultural 57 rural parts of the landscape (Chicago-Wilderness, 2004). In the rural parts of the Midwestern US, 58 intensive agricultural production has persisted into the modern era resulting in relatively little 59 forest regrowth related to agricultural abandonment. Highly urbanized areas in this region could, 60 therefore, have retained equivalent or greater levels of remnant forest (and connectivity between 61 these ecosystems) than surrounding rural landscapes. However, in contrast to urban areas in arid 62 regions, this effect would be more strongly related to development patterns than eco-climatic 63 factors (Nowak et al., 1996).

64 Absolute canopy cover and the connectivity of this cover is extremely important to many of 65 the ecosystem benefits associated with trees and forests in urban regions (Nowak \& Walton, 66 2005). However, whether or not this cover is constituted by remnant forest patches, spontaneous 67 forests (naturally regenerated following initial clearing for urban or agricultural development), or 68 intentionally planted trees could make a very large difference for some ecological functions and 69 could be very important to the overall functioning of urban region landscapes (Nowak, 1993; 
Zipperer, 2002). Remnant forests have been shown to support greater biodiversity, store more carbon, and have fewer invasive species relative to spontaneous forests (Dupouey et al., 2002; Zipperer, 2002). Patterns of development over time are likely to have had a great impact on the balance of remnant versus spontaneous/planted forests and, thus, also on ecosystem functions and services associated with urban regions. It can be difficult to determine whether urban canopy cover is associated with remnant or spontaneous/planted forests, but investigation of a timeseries of imagery can aid such assessment (Qian et al., 2015; Ward et al., 2007; Zhou et al., 2011).

Historically, the wooded ecosystems of central North America were highly dominated by oaks (Quercus spp.), which functioned as foundational species in these ecosystems by creating structure, providing habitat, and driving disturbance regimes (Abrams, 2003). There has been a significant reduction in the dominance of oaks across this region over the past two centuries, due to a variety of direct and indirect anthropogenic impacts (Abrams, 2003; Lorimer, 1993) as well as climatic shifts (McEwan et al., 2011). For example, in the highly urbanized Chicago metropolitan region, the dominance of oak has been reduced from $\sim 60 \%$ of the basal area at the time of Euro-american settlement in the 1830's to 20\% in the modern era (Fahey et al., 2012). Although decreases in oak dominance have resulted from compositional shifts related to successional processes and changes to disturbance regimes (Bowles et al., 2005), a primary factor in the loss and fragmentation of oak ecosystems has been urban and agricultural development (Fahey et al., 2012; Kromroy et al., 2007; Ward et al., 2007). Remnant forests are more likely to have retained oaks (and other associated native species) as a component of the ecosystem and thus provide the benefits associated with these species. Understanding changes in the area dominated by these remnant ecosystems and fragmentation of remnant patches will be 
93 essential to assessing functional changes in the landscape related to urban development (Ward et 94 al., 2007).

96 (which were largely oak-dominated) over the past $~ 180$ years (1830's to present) in the greater

97 Chicago metropolitan region, to assess the impact of landscape features and development

98 patterns on the preservation or conversion of these ecosystems, and to compare patterns of forest 99 conversion and fragmentation in this region to other urban areas. Our first specific goal

100 (Objective 1) was to understand how the spatial distribution of forest ecosystems has changed 101 over time across land uses and a gradient in urbanization - including how core habitat and 102 connectivity in this ecosystem type have changed. Our second goal (Objective 2) was to assess 103 what specific landscape features and sociodemographic factors have been associated with 104 conversion of forest ecosystems in this landscape. Finally, we also evaluate how the species 105 composition and structure of remnant forest ecosystems differ from the urban forest of the region 106 as a whole (Objective 3).

\section{Methods}

109 Study area

110 The study area encompassed the Illinois portion of the Chicago metropolitan region, which 111 covers $18,822 \mathrm{~km}^{2}$ and all or part of 18 counties (Fig. 1). The Chicago region is home to $\sim 9$

112 million people and contains a wide variety of land uses, cultural and social milieus, population 113 densities, and around 145,000 ha of natural reserves (Chicago-Wilderness, 2004). The surficial 114 geology of the Chicago region includes glacial material deposited in the last 20,000 years, 115 primarily glacial drift (end moraines, till plains and outwash) and the former bed of glacial Lake 
116 Chicago (Willman, 1971). The area is located within the "Prairie Peninsula" (Transeau, 1935),

117 a region with unpredictable summer drought (Borchert, 1950). The pre-Euroamerican

118 settlement landscape of the Chicago region was about 60-80\% grassland, with the remainder

119 comprised of a savanna-woodland-forest gradient corresponding to increasing fire protection

120 (Bowles et al., 1994; McBride \& Bowles, 2001). Wooded ecosystems at the time of settlement

121 were largely constrained to fire breaks along the east side of major waterways and other fire-

122 protected landscape positions (Fahey et al., 2014; Fahey et al., 2012).

123

Forest ecosystem mapping and data sources

125 Data on the areal extent of forest ecosystems were collected for three time periods - the

1261830 's, 1939, and 2010. Data on vegetation for the pre-Euroamerican settlement era (1830's)

127 were derived from information recorded in the General Land Office Public Land Survey (PLS)

128 notes, which were collected in the region in the period of 1821-1845. The PLS comprised a

129 square-mile landscape grid where the identity, diameter, distance, and direction of one to four

130 bearing trees were recorded at half mile intervals and were accompanied by notation of

131 vegetation intercepted along section lines. Although there may have been some bias in witness

132 tree selection by surveyors in the PLS, these data and derived maps represent a large-scale

133 vegetation survey that can be used to reconstruct landscape-scale vegetation composition and

134 pattern (Schulte \& Mladenoff, 2001). PLS-era vegetation maps were developed based on the

135 Chicago region PLS notes, surveyor plat maps, and modern maps relating the distribution of

136 forest-associated soil types (i.e., Alfisols) (full method detailed in Bowles \& McBride, 2005;

137 maps available at http://plantconservation.us/plsmap.phtml). These maps were used to assess

138 the general pre-settlement distribution of wooded ecosystems (areas identified as "timber", 
"scattering timber", or "barrens" in the survey notes) across the region. To support specific understanding of trends in oak ecosystems for regional planning purposes, witness tree data were used to determine which of these ecosystems had an oak component in the PLS era (Schulte \& Mladenoff, 2001). Bearing and line tree data recorded in the PLS illustrate that the vast majority of forested areas in the region had oak trees present (Fahey et al., 2014; Fahey et al., 2012). In the seven county region (for which witness tree data is available as spatial data), only 3,600 hectares out of an overall 305,571 ha $(\sim 1 \%)$ had no evidence for an oak component (i.e., no oak witness trees present in adjacent witness tree records). Thus, forest ecosystems with an oak component represented the vast majority of wooded ecosystems in the region and the patterns illustrated here reflect changes in that resource.

Remnant forest ecosystem extent in 1939 and 2010 was evaluated based on analysis of aerial imagery within the original PLS forest ecosystem areas. Manual aerial image analysis was utilized in this regional analysis (rather than automated methods) to match methods previously applied in county-level analysis in McHenry and Lake counties (McHenry-CountyConservation-District, 2009). Analysis was conducted by a single person with quality control checking and field ground-truthing (on modern imagery) assistance by multiple partners. Areas in the 1939 georectified aerial images (https://clearinghouse.isgs.illinois.edu/) identified as having large canopy trees and that fell within or in the vicinity of the PLS forest ecosystem layer were digitized into a 1939 remnant forest ecosystem layer. In this analysis, only forest patches that were located within areas identified as forest/woodland/savanna/barrens in the PLS or near these areas (and with forest soils) were counted as "remnant" forests. Therefore some older forests that arose around the time of settlement (mid to late 1800's) may not have been included in this analysis and the remnant forest definition likely slightly underestimates the amount of 
162 older forest in the region. Parcels identified in the 1939 images were then compared to 2010

163 NAIP orthoimagery and reshaped or removed to reflect current remnant forest ecosystem extent.

164 Only parcels greater than 0.4 ha (1 acre - an arbitrary threshold established by McHenry County

165 Conservation District, the originators of the project) that were not divided by roads or other

166 barriers were included in the layers. Sites that retained some canopy but were developed into

167 residential or urban land uses were not counted as remnant forest ecosystems.

168 Comparing forest ecosystem extent among the three time periods is complicated by the fact

169 that the process of mapping forest ecosystems from the PLS necessarily differed from that used

170 on the aerial imagery from 1939 and 2010. The pre-settlement landscape was almost certainly

171 more of a fine-grained patchwork than is represented by the PLS-derived maps, and the large

172 polygons derived from the PLS likely included open areas mixed within more heavily wooded

173 ecosystems. These would have included areas that were recently or frequently burned, producing

174 open savannas or barrens rather than closed canopy forests. In the modern landscape, areas

175 separating canopy patches are often either developed urban land or agricultural fields, which do

176 not have equivalent value as ecosystems and present more significant barriers for many species.

177 In the modern image analysis, areas that had sparse or discontinuous canopy were included as a

178 single parcel if the area connecting the canopy was not in an urban or agricultural land use or

179 occupied by another vegetation type (e.g., open wetland, conifer plantation). Recreating the PLS

180 method of delineating forest ecosystems in the modern landscape would doubtless have produced

181 much more aggregated parcels, but these would not represent the same functionally connected

182 ecosystems as the patches in the PLS era.

183 A number of datasets were used to evaluate factors associated with retention of forest

184 ecosystems in the region. These included: land-use data from the Chicago Metropolitan Agency 
185 for Planning (CMAP; http://www.cmap.illinois.gov/data/land-use/inventory), sociodemographic 186 data from the US Census Bureau data (US-Census-Bureau, 2010) - specifically median income 187 and household density which are straightforward proxies for urban density and economic status, 188 data on timing of municipal incorporation (Illinois Secretary of State; http://www.ilsos.gov/), 189 ownership and protected status data from the Chicago Wilderness Green Infrastructure Vision 190 (Chicago-Wilderness, 2004), and watershed and landform data 191 (https://clearinghouse.isgs.illinois.edu/). The CMAP region only covers seven counties (Cook, 192 DuPage, Lake, Kane, Kendall, McHenry, and Will); therefore land use data developed by that 193 agency do not cover the entire study region.

\section{Data analysis}

To assess change in forest ecosystem area and landscape structure over time in the Chicago

197 region (Obj. 1) the total area of the PLS, 1939 and 2010 remnant forest ecosystem data layers 198 were calculated as well as the size of each parcel. In addition, parcel sizes were recorded and 199 tabulated by county, watershed, and for land use categories. For each parcel in the 2010 data set 200 the ownership type (private vs. public) and protected status of the parcel were identified and 201 protected land parcels were classified based on type of organization/ownership. Parcel size was 202 assessed for raw parcels in each time period and also with parcels aggregated at distances of 100 and 200m using ArcGIS v. 10.2 (ESRI-Inc., 2015) for the 2010 layer only. Aggregation was

204 performed with the goal of combining parcels in relatively close proximity that might be 205 viewed/utilized as contiguous habitat by certain mobile species.

To assess fragmentation and changes in the structure of the landscape we calculated core 207 area (based on a 100m edge depth definition) and landscape metrics for the PLS, 1939, and 2010 
208 forest ecosystem layers as well as the aggregated 2010 layers using PatchAnalyst in ArcGIS 10.2 209 (Rempel et al., 2012). Landscape metrics that were calculated included: mean and median patch 210 size, perimeter to area ratio, mean shape index, mean fractal dimension, edge density, and patch 211 size coefficient of variation (McGarigal, 2013). Connectivity was evaluated based on nearest 212 neighbor distances between patches. The ratio of observed to expected nearest neighbor distance 213 (based on number of patches per unit area) was calculated to remove the effect of increasing 214 patch number with increasing fragmentation. As noted above, differences in spatial grain of 215 patches derived from PLS and aerial imagery analysis make direct comparisons between the time 216 periods not quantitatively meaningful. Patches present at the time of the PLS were likely less 217 aggregated than reflected in the data, but were also not separated by non-habitat patches such as 218 the urban land uses prevalent in the modern landscape.

219 Variation in protected status and measures of fragmentation and connectivity were assessed 220 at the county scale and related to urbanization gradients across the region. We conducted 221 analysis at the broad county scale (rather than census tracts used below) because many decisions 222 related to land use and conservation are made at the county level, analysis of patch 223 characteristics is not meaningful at fine scales, and because counties in the Chicago region align 224 relatively well with an urbanization gradient (Table 2). Comparisons across these counties allow 225 for broad-scale analysis, while capturing an urban to rural gradient with a stable definition of 226 units. We assessed the correlation of these variables and their change from 1939 to 2010 with 227 sociodemographic variables including: 2010 population density, 2010 percent urban population, 2282010 median income, and percent change in population from 1940 to 2010. Relationships were 229 evaluated with simple linear regression using Sigmaplot 13.0 (SYSTAT-Software-Inc., 2015). 
To evaluate factors associated with preservation/conversion of forest ecosystems (Obj. 2),

231

232

233

234

235

236

237

238

239

240

241

242

243

244

245

246

247

248

249

250

251

252

the 2010 layer was first overlaid on the PLS layer and converted to a raster (1ha pixels). Each

pixel in the original PLS forest ecosystem was then classified as either "preserved" or

"converted". Conversion was compared among counties, land uses classes, and watersheds, using 2 x C Contingency Table Analysis on counts of pixels. In addition, percent forest ecosystem retention was calculated for each census tract (small, relatively permanent statistical and geographical subdivisions of a county delineated by the US Census Bureau) as the proportion of pixels that were preserved. For each tract we also determined percent impervious surface cover (based on National Land Cover Dataset; Homer et al., 2015), mean distance to stream, and household density and median income (US-Census-Bureau, 2010). The relationship between tract-level percent retention and these predictors was then assessed using multiple regression in an information theoretic framework using PROC MIXED in SAS v.9.4 (SASInstitute-Inc., 2015). We also assessed the factors associated with conversion or preservation of individual 1ha pixels using multiple logistic regression with PROC LOGISTIC in SAS.

Predictors included were: percent impervious surface, distance to stream, household density and median income (based on census tract values), and land-use class. Finally, to assess whether forest ecosystem retention was related to timing of settlement/development we assessed the relationship between percent retention at the municipal scale and the date of incorporation for each municipality using simple linear regression.

Characteristics of remnant ecosystems relative to the urban forest as a whole (Obj. 3) were evaluated based on analysis of plot data from the Chicago Region Tree Census conducted by The Morton Arboretum and USDA Forest Service in 2007 and 2010 (Nowak et al., 2013). This data set includes 2076 plots located in stratified random fashion across land use types and counties 
253 and covering the seven CMAP counties. In each 0.04 ha plot, all trees $>2.5 \mathrm{~cm}$ in diameter at

$2541.37 \mathrm{~m}$ were measured for diameter, height, and canopy dimensions. In order to compare

255 characteristics of spontaneous and planted forests with remnant forests, only plots with current

256 tree cover were analyzed (564 plots). Plot locations were overlaid on the three forest ecosystem

257 layers to group them into the following categories: 1) non-forest in PLS era, 2) converted prior to

258 1939, 3) converted between 1939 and 2010, and 4) remnant in 2010. The first three categories

259 represent urban land uses with some tree canopy or spontaneous/planted forests of different

260 potential ages. For example, plots in category 2 represent developed areas (either urban or

261 agricultural) converted from their original forested condition (according to the PLS), but that

262 have trees present (e.g., street trees or landscape trees), which could be remnant, spontaneous, or

263 planted in origin. Characteristics of the tree communities recorded in the Tree Census plot data

264 were compared among these categories using analysis of variance (ANOVA) including: canopy

265 cover, total basal area, standing dead basal area, oak dominance, non-native species dominance,

266 maximum diameter, and maximum canopy height. ANOVA tests were conducted using

267 Sigmaplot 13.0 and for each characteristic, individual comparisons were made using the Holm-

268 Sidak multiple comparison test.

270 Results

271 By 1939 there was already a strong decrease in the areal extent of forest ecosystems

272 compared to estimates for the pre-Euro-American era. At this point 113,254 hectares of the

273 original forest ecosystem remained intact, which represents $\sim 27 \%$ of the original area (Table 1 ,

274 Fig. 1). In the time interval from the 1830 's to 1939 the annual loss of forest ecosystem area was

$275 \sim 3000$ hectares per year (based on 1832 as a starting point). Retention rates for this time period 
276 were highest for rural, western counties such as LaSalle (50\%), Kendall (43\%), and Grundy

$277(42 \%)$ where wooded ecosystems were concentrated along large river systems (Table 2, Fig. 1).

278 Lowest retention occurred in the northwestern rural counties of Boone (14\%) and McHenry

279 (15\%) which had more dispersed original forest ecosystems (Table 2, Fig. 1).

280 In the period between 1939 and 2010 there were significant additional losses of remnant

281 forest ecosystem area. By 2010 there were 69,958 hectares of remnant forest ecosystem in the

282 region, which represents $\sim 17 \%$ of their original area (Table 1, Fig. 1). This also represents $\sim 40 \%$

283 reduction in area relative to the 1939 time period. The annual loss of forest ecosystem area over

284 this time period was $\sim 600$ hectares per year. The lowest retention rates during the 1939 to 2010

285 time period were in suburban counties such as DuPage (46\%), Lake (50\%) and Kane (55\%)

286 counties. Highest retention rates in this time period occurred in rural LaSalle (79\%), Grundy

287 (74\%), and Ogle (73\%) counties.

288 Although there were strong differences among counties in the degree to which forest 289 ecosystems were retained into the modern era (relative to both the PLS era and 1939; Table 2,

290 Fig. 2), these differences were not strongly correlated with population density, urbanization, 291 population growth, or median income (all $\mathrm{r}<0.3$; Table A1 in Supplementary Material). There

292 was high variability in retention among municipalities, and date of incorporation of the

293 municipality was weakly related to percent forest ecosystem conservation $(r=0.36, p=0.005$;

294 Fig. C1 in Supplementary Material).

295

Parcel size and fragmentation

297 In the period between 1939 and 2010 there were high levels of fragmentation of remnant

298 forest ecosystems. Although there had been high levels of conversion from the original landscape 
by 1939 , there were nonetheless a significant number of large remnant parcels (e.g., 27 parcels $\geq$

300

301 200 hectares; Table 1). The distribution of parcel sizes shifted strongly toward greater representation of smaller parcels by 2010 (Table 1; see Fig. C2 in Supplementary Material for full frequency distribution). By the modern era most large parcels had been fragmented and only 6 parcels greater than 200 hectares remained intact. Between 1939 and 2010 mean patch size declined greatly and perimeter to area ratio and edge density both greatly increased (Table 3 ). Core area (area >100m from patch edge) declined greatly between 1939 and 2010 and at a much higher rate than forest ecosystem area overall (42\% retention of core area vs. $61 \%$ overall). In addition, only 141 of $322(44 \%)$ core parcels $\geq 10$ ha in area remained intact in 2010 . Levels of fragmentation were dependent to some extent on the definition of a continuous ecosystem. If parcels within $100 \mathrm{~m}$ or $200 \mathrm{~m}$ of each other were aggregated there were many more large semicontiguous ecosystems, but still far fewer than in the pre-settlement landscape (Table 1).

Parcel sizes and degree of fragmentation or connectivity varied greatly across the landscape (Table 3) and appeared to be strongly related to patterns of population growth and urbanization (Fig. 3). Both percent retention of core area from 1939 to 2010 and change in nearest neighbor ratio (increased isolation of patches) were related to percent change in population at the county scale during that same time period (1940-2010). Edge density tended to increase with increasing urbanization (percent urban population at the county scale; US-Census-Bureau, 2010). The relationship of fragmentation with urbanization and population growth was not consistently strong across all metrics (see Table A1 in Supplementary Material). However, the direction of these relationships tended to be consistent and illustrate positive correlations between urbanization and fragmentation. 


\section{Ownership and protected status}

Approximately $30 \%$ of the remnant forest ecosystem area identified in the 2010 imagery analysis was in some type of protected status, which represents approximately $5 \%$ of the original pre-settlement forest ecosystem (Table 1$)$. The majority of these protected parcels $(74 \%)$ were in local ownership - primarily as county forest preserves (see Table A2 in Supplementary Material for ownership detail). The degree to which remnant forest ecosystems were protected varied greatly across the region (Table 2). There were very strong positive relationships between the degree of protection of remnant forest ecosystems and population density and urbanization (Fig 3a, Table A1 in Supplementary Material). In highly urbanized Cook County $80 \%$ of the remnant forest ecosystem was in some form of protected status, whereas the protected proportion was generally much lower in rural counties ( $<10 \%$ in some counties; Table 2$)$. Protected parcels also tended to be small and fragmented; for example in 2010 there was only one protected parcel $\geq$ 200 hectares in area and only 67 protected core parcels $\geq 10$ ha.

\section{Forest ecosystem retention in relation to landscape characteristics}

Retention of forest ecosystems was highly variable among modern land use classes $\left(\mathrm{X}^{2}=\right.$ 107.0, $\mathrm{df}=8, \mathrm{p}<0.001$ ), with much greater retention in open space (areas reserved for conservation or recreational uses; $37 \%$ ) and vacant areas (areas with no active land use or management; 28\%) than any other land uses (Fig. 2). Retention did not differ among watersheds, as all had between 10 and $32 \%$ retention.

The strongest predictors of forest ecosystem retention at the census tract scale were distance to stream and percent impervious surface. The model incorporating these two factors was more strongly supported than any other in the set $(\triangle A I C=3.3$, Table 4$)$ and was very highly weighted 
345 relative to the model set as a whole $\left(w_{i}=81 \%\right)$. Forest ecosystem retention was much more

346 likely in areas in close proximity to streams and where there was lower impervious surface area

347 in the vicinity (Fig. 4).

348 At the scale of individual tha areas of original forest ecosystem, retention was best

349 explained by a combination of impervious surface area, household density, distance to stream,

350 and land use. The model comprised of all four of these factors and that with household density

351 removed were not distinguishable based on AIC and together accounted for $99 \%$ of the

352 weighting in the model set (Table 4). Household density and impervious surface were highly

353 correlated $(\mathrm{r}=0.74)$, thus the simpler model comprised of impervious surface, distance to

354 stream, and land use was interpreted. Probability of retention was greater with closer proximity

355 to stream and less impervious surface, but the strength and shape of these relationships differed

356 greatly among land uses (Fig. 5). Probability of retention was especially low in areas of

357 agricultural land use.

358

\section{Characteristics of remnant and non-remnant forest ecosystems}

360 Characteristics of 2010 regional Tree Census plots varied strongly with timing of

361 establishment (Table 5). Locations that were identified as remnant ecosystems in the 2010

362 landscape had much higher canopy cover, total basal area, snag basal area, oak dominance,

363 maximum diameter, and maximum canopy height and lower non-native dominance than other

364 areas with trees present in the 2010 Tree Census. Areas that were converted from forest to urban

365 or agricultural land use after 1939 (but had some trees present in the 2010 Tree Census) tended

366 to be relatively similar to remnant ecosystems except in terms of snag basal area, maximum

367 canopy height, and non-native dominance. Areas converted from forest to other land uses prior to 
1939 tended to be intermediate between areas converted after 1939 and areas that were non-

369 forest in the PLS era in all respects except snag BA (Table 5).

\section{Discussion}

372 Landscape pattern of remnant forest ecosystems in relation to development

373 Conversion of forest ecosystems in the Chicago region followed a distinctive pattern that

374 was driven by a combination of physical landscape structure, original vegetation conditions, and

375 subsequent urban and agricultural development patterns (Burgess \& Sharpe, 1981; McBride \&

376 Jacobs, 1986; Sanders, 1984; Sharpe et al., 1986). Remnant forests are limited by definition to

377 the vegetation conditions that existed at the time of settlement, thus in the Chicago region these

378 forests are often constrained to fire-protected areas such as the east sides of major waterways

379 (Fahey et al., 2014). The finding that proximity to waterways also had an important effect on the

380 probability of forest conversion, likely reflects the tendency of the early land preservation

381 movement to focus on densely-canopied forests along major rivers or that these areas were

382 avoided during agricultural development because of frequent flooding (Smith, 2009). There

383 could also be an influence of more recent development patterns; for example, areas in

384 floodplains may have been less likely to be converted into urban land uses. These findings

385 illustrate that the geographic position of forests at the time of settlement has been very important

386 to the modern structure of the landscape, making the "snap-shot" provided by the PLS surveys

387 especially important in this instance (Rhemtulla et al., 2009). On the other hand, the strong

388 relationships of land-use and impervious surface with forest conversion indicate a direct effect of

389 development and urbanization on forest ecosystem retention (Kromroy et al., 2007). 
In a landscape such as the Chicago region, which was fragmented by the disturbance regime prior to urban development (Fahey et al. 2014), there may be a lower relative effect of urbanization on connectivity than in more densely forested regions. In this landscape, overall conversion of forest ecosystems was not especially greater in highly urbanized parts of the region. This finding contrasts results from regions with more continuous forest cover where development in the urban core had a disproportionately large effect on forest cover and fragmentation (Civco et al., 2002; Miller, 2012; Radeloff et al., 2005; Riitters et al., 2002; Zhou et al., 2011). This difference was likely associated with both the configuration of the presettlement landscape and subsequent (and related) patterns of agricultural development, on which urbanization was superimposed. Also, in this landscape the combination of urbanization and the relatively fragmented starting point have resulted in a landscape with especially low regional connectivity (Chicago-Wilderness, 2004). Although some areas have retained local connectivity, especially some of the river corridors, these areas are isolated from other remnant ecosystems (Fig. 1). Recent suburban and exurban development also appear to have had an especially strong influence on the spatial landscape patch structure of the remnant forest ecosystems of the region over the past $\sim 70$ years (Zhou et al., 2011). Areas with rapidly increasing populations in this time period had especially strong decreases in core habitat, especially high levels of fragmentation, and large decreases in connectivity (Civco et al., 2002; Dallimer et al., 2011; Iverson \& Cook, 2000). The effect of suburban development on forest fragmentation is widely recognized (Miller, 2012; Radeloff et al., 2005; Zhou et al., 2011), but may have been especially intense in this naturally fragmented landscape.

Pervasive and persistent agricultural development in rural areas may also help explain the limited relative effect of intense urbanization in this landscape. The landscape surrounding 
413 Chicago supports intense agriculture and has undergone extreme levels of conversion of natural

414 ecosystems (Chicago-Wilderness, 1999). The prairies that were the other dominant ecosystem

415 type in the pre-Euroamerican landscape have been almost entirely converted (Samson \& Knopf,

416 1994), but forests have also been subject to conversion and fragmentation due to agricultural

417 development (Fahey et al., 2012). In this analysis, the probability of forest conversion was

418 greatest in agricultural land uses, even relative to commercial and industrial land uses (Fig. 5)

419 and the areas with the highest percent conversion were rural Boone and McHenry counties

420 (Table 2). The intensity of agricultural development has resulted in a landscape that is relatively

421 uniform in terms of conversion and fragmentation, in comparison to other urban regions where

422 the primary development in surrounding rural areas has been more recent exurban development

423 (Kromroy et al., 2007; Miller, 2012; Zhou et al., 2011).

424 Although highly urbanized areas had the greatest degree of forest conversion and

425 fragmentation, the forests that remained in these areas also had a greater degree of protection,

426 reflecting the importance of natural areas reserve networks (Pickett et al., 2008). There was a

427 very strong positive relationship between the percent of remnant ecosystems in protected land

428 status and the density of population in each county (Fig. 3a). Highly urbanized Cook and DuPage

429 counties (Table 2) had the highest proportion of their remnant forests in protected status. This

430 pattern was not just a function of higher conversion rates, as Cook County had more remnant

431 forest in protected status than all but three other counties had remaining overall (regardless of

432 protected status). In these counties, as well as the other mostly urban/suburban inner counties

433 (Kane, Lake, McHenry, and Will), the majority of the protected remnant forest is in natural areas

434 owned by county forest preserve districts. The creation of this reserve network may have 
435 alleviated the effects of development, resulting in urban core areas that have retained more remnant forest and more connectivity than some parts of the surrounding agricultural landscape.

Characteristics of remnant, non-remnant, and developed forest ecosystems

Even though remnant forests are a relatively minor component of the overall modern

440 Chicago region landscape ( $4 \%$ of the landscape), they likely provide disproportionate value to 441 the ecology of the region (Fahey et al., 2012; Zipperer, 2002). These remnant ecosystems harbor

442 some of the largest trees in the region and have especially high basal area (and thus carbon 443 storage). These ecosystems are also likely to be important wildlife habitat for some species, as 444 evidenced by high volumes of standing dead wood and an especially tall/deep canopy layer 445 (McShea \& Healy, 2002; Rodewald \& Matthews, 2005; Wood et al., 2014). These remnant 446 ecosystems also were more "healthy" in other respects, for example they had much lower 447 invasive species dominance than other forested areas (Zipperer, 2002). The preservation of these 448 ecosystems may be essential to the integrity of the regional ecosystem (Ward et al., 2007), but 449 strict focus on preservation is likely to lead to continued degradation of the value of these forests. 450 The high canopy cover of these areas is a positive in some respects (such as providing shade for 451 humans and other animals; Nowak et al., 2013), but is also likely a factor in the consistent lack 452 of oak regeneration evident in the region (Carter et al., 2015; Fahey et al., 2014; Lorimer, 1993). 453 Active restoration (e.g., prescribed fire or canopy thinning) is likely to be necessary in many of 454 these forests, both to maintain the low dominance of invasive species (Knight et al., 2007), and 455 to provide conditions that can promote biodiversity and continued dominance of important native 456 canopy species such as oaks and hickories (Dey et al., 2010). 
Although many forested patches within the landscape have been converted to urban land

458

uses, some of these areas have retained some remnant forest canopy (Chicago-Wilderness, 2015). This is reflected in the high basal area and canopy cover of areas converted to urban land uses after 1939 relative to forested areas in the landscape as a whole and areas converted to urban and agricultural land uses prior to 1939 (Table 5). This pattern likely has much to do with the nature of suburban conversion relative to earlier urban and agricultural development (Bigsby et al., 2014). More canopy is likely to be retained in the process of suburban residential development than urban or agricultural development. Suburban and exurban areas have therefore retained some of the characteristics of remnant forests and the canopy in these areas is likely still highly valuable both for ecosystem services and to the residents of these areas (Nowak, 1993; Zipperer, 2002). However, additional work is needed to assess the ecosystem service value of these areas and whether they can provide habitat connectivity between remnant patches (Angold et al., 2006; Rudd et al., 2002). Characteristics of the ecosystem beyond the canopy layer (e.g., groundcover, understory structure, woody debris) are likely to have a very strong influence on the suitability of these areas as habitat or movement corridors.

The dominance of oaks varied greatly among the categories of development timing, reflecting the importance of remnant forests for the regional oak resource (Table 5). There are certainly some oak-dominated forests that have established in areas that were not part of the original forest, or were converted from the original ecosystem and then subsequently reverted to oak dominance (Zhou et al., 2011). Although these areas are not likely to have the same structural and functional characteristics as the remnant ecosystems, they nonetheless could also form an important component of the regional oak resource. These forests will become especially important in the future as they become more similar to the remnant ecosystems in age and size 
structure (Zipperer, 2002). Further effort is needed to identify these areas to attempt to document the totality of oak ecosystems in the region. Such efforts could rely on remote sensing and image analysis approaches to delineate areas with oak dominance and inform targeted field surveys to assess composition and structure (Gu et al., 2015; Ward et al., 2007).

\section{Implications for urban forest landscape management}

In urban and suburban parts of the Chicago region, the existing high levels of protection for remnant forest patches indicates that there may be little opportunity to increase connectivity by adding protection to remnant forests. In some situations, barriers between remnant ecosystems are essentially permanent features of the urban landscape, such as highways or other transportation corridors, where canopy cannot be readily re-introduced (Chicago-Wilderness, 2015). In other cases, though, there may be significant opportunities to utilize components of the urban landscape as connectors between ecosystems. In urbanized landscapes the primary mechanism for connecting remnant forests is likely to be reforestation/reclamation in areas previously in urban land uses or urban canopy enhancement focused on native species (Rudd et al., 2002). Developed areas with some remnant trees could be important connections or buffers for remnant ecosystems, but so could areas that are newly managed for an native species component in the planted tree population (Chicago-Wilderness, 2015). Reforestation or revegetation of vacant land with native species as a component of the planting pool, in both the canopy and groundlayer, could be another avenue for expanding or enhancing the value of existing remnant forest ecosystems (Robinson \& Handel, 2000).

In rural and exurban portions of the region there may be more opportunities for putting additional remnant forest patches into some form of protected status as well as connecting 
503 remnant patches with either remnant or restored ecosystems. In more rural parts of the region,

504 much of the fragmentation is related to agricultural usage that is unlikely to revert to open space

505 in the foreseeable future, but there are still likely to be many private parcels that may be

506 acquirable or could be targeted for conservation easements (Rissman et al., 2007). Some remnant

507 ecosystems even exist within larger matrices of open space, but may be separated by different

508 ecosystem types (e.g., wetlands) or non-native vegetation (e.g., conifer plantations). Conversion

509 of non-native vegetation to native/oak-dominated vegetation in these locations should be a

510 priority for managers (Chicago-Wilderness, 2015). Further analysis is ongoing to identify and

511 prioritize opportunities for creating connections between remnant ecosystems across the wide

512 variety of milieus present within this large urban landscape.

513 


\section{References}

Abrams, M. D. (2003), Where has all the white oak gone?, BioScience, 53(10), 927-939.

Anderson, R. C. (1991), Presettlement forests of Illinois, in: Proceeding of the Oak Woods Management Workshop. (G. V. Burger, J. E. Ebinger, G. Wilhelm, eds.), Eastern Illinois Univ., Charleston, IL, pp. 9-19.

Angold, P., Sadler, J. P., Hill, M. O., Pullin, A., Rushton, S., Austin, K., Small, E., Wood, B., Wadsworth, R., \& Sanderson, R. (2006), Biodiversity in urban habitat patches, Science of the Total Environment, 360(1), 196-204.

Bigsby, K. M., McHale, M. R., \& Hess, G. R. (2014), Urban morphology drives the homogenization of tree cover in Baltimore, MD, and Raleigh, NC, Ecosystems, 17(2), 212-227.

Borchert, J. R. (1950), The climate of the central North American grassland, Annals of the Association of American Geographers, 40(1), 1-39.

Bowles, M., Hutchison, M., \& McBride, J. (1994), Landscape pattern and structure of oak savanna, woodland, and barrens in northeastern Illinois at the time of European settlement, in: Proceedings of the North American Conference on Savannas and Barrens. (J. S. Fralish, R. C. Anderson, J. E. Ebinger, R. Szafoni, eds.), Illinois State University, Normal., pp. 65-74.

Bowles, M., Jones, M., McBride, J., Bell, T., \& Dunn, C. (2005), Temporal instability in Chicago's upland old growth forests, Chicago Wilderness Journal, 3(2), 5-16.

Bowles, M., \& McBride, J. (2005), Pre-European settlement vegetation of Lake County, Illinois, Technical Report. The Morton Arboretum, Lisle, IL. http://www.plantconservation.us/BowlesMcBrideLake.pdf.

Burgess, R. L., \& Sharpe, D. M. (1981), Forest island dynamics in man-dominated landscapes, Springer-Verlag.

Carter, D. R., Fahey, R. T., Dreisilker, K., Bialecki, M. B., \& Bowles, M. L. (2015), Assessing patterns of oak regeneration and $\mathrm{C}$ storage in relation to restoration-focused management, historical land use, and potential trade-offs, Forest Ecology and Management, 343 53-62.

Chicago-Wilderness (1999), Biodiversity recovery plan, Chicago Wilderness, Chicago, IL, USA, pp. 147.

Chicago-Wilderness (2004), Chicago Wilderness Green Infrastructure Vision: Final Report, Chicago Wilderness, Chicago, IL, USA.

Chicago-Wilderness (2015), Oak Ecosystems Recovery Plan: Sustaining Oaks in the Chicago Wilderness Region, Chicago Wilderness, Chicago, IL, USA, pp. 42.

Civco, D. L., Hurd, J. D., Wilson, E. H., Arnold, C. L., \& Prisloe, M. P. (2002), Quantifying and describing urbanizing landscapes in the Northeast United States, Photogrammetric Engineering and Remote Sensing, 68(10), 1083-1090.

Dallimer, M., Tang, Z., Bibby, P. R., Brindley, P., Gaston, K. J., \& Davies, Z. G. (2011), Temporal changes in greenspace in a highly urbanized region, Biology Letters, 7(5), 763 766.

Dey, D. C., Royo, A. A., Brose, P. H., Hutchinson, T. F., Spetich, M. A., \& Stoleson, S. H. (2010), An ecologically based approach to oak silviculture: a synthesis of 50 years of oak ecosystem research in North America, Revista Colombia Forestal, 13(2), 201-222.

Dupouey, J., Dambrine, E., Laffite, J., \& Moares, C. (2002), Irreversible impact of past land use on forest soils and biodiversity, Ecology, 83(11), 2978-2984.

ESRI-Inc. (2015), ArcGIS 10.2. ESRI Inc., Redlands, CA. 
Fahey, R., Maurer, D., Bowles, M., \& McBride, J. (2014), Evaluating restoration baselines for historically fire-protected woodlands within a Northeastern Illinois Prairie Peninsula landscape, Natural Areas Journal, 34(2), 166-177.

Fahey, R. T., Bowles, M., \& McBride, J. (2012), Origins of the Chicago urban forest: composition and structure in relation to pre-settlement vegetation and modern land-use, Arboriculture and Urban Forestry, 38(5), 181-193.

Gillespie, T. W., Pincetl, S., Brossard, S., Smith, J., Saatchi, S., Pataki, D., \& Saphores, J.-D. (2012), A time series of urban forestry in Los Angeles, Urban Ecosystems, 15(1), 233 246.

Gu, H., Singh, A., \& Townsend, P. A. (2015), Detection of gradients of forest composition in an urban area using imaging spectroscopy, Remote Sensing of Environment, 167 168-180.

Homer, C. G., Dewitz, J. A., Yang, L., Jin, S., Danielson, P., Xian, G., Coulston, J., Herold, N. D., Wickham, J., \& Megown, K. (2015), Completion of the 2011 National Land Cover Database for the conterminous United States-Representing a decade of land cover change information, Photogrammtric Engineering and Remote Sensing, 81(5), 345-354.

Iverson, L. R., \& Cook, E. A. (2000), Urban forest cover of the Chicago region and its relation to household density and income, Urban Ecosystems, 4(2), 105-124.

Knight, K. S., Kurylo, J. S., Endress, A. G., Stewart, J. R., \& Reich, P. B. (2007), Ecology and ecosystem impacts of common buckthorn (Rhamnus cathartica): a review, Biological Invasions, 9(8), 925-937.

Kromroy, K., Ward, K., Castillo, P., \& Juzwik, J. (2007), Relationships between urbanization and the oak resource of the Minneapolis/St. Paul Metropolitan area from 1991 to 1998, Landscape and Urban Planning, 80(4), 375-385.

Lorimer, C. G. (1993), Causes of the oak regeneration problem, in: Oak Regeneration: Serious Problems, Practical Recommendations, USDA Forest Service General Technical Report SE-84, Southeastern Forest Experiment Station, Asheville, North Carolina, pp. 14-39.

McBride, J. L., \& Bowles, M. L. (2001), Vegetation pattern of DuPage and Will counties at the time of European settlement. In: Proceedings of the 12th Northern Illinois Prairie Conference. C. Peterson, ed. College of DuPage, Glen Ellyn, IL.

McBride, J. R., \& Jacobs, D. F. (1986), Presettlement forest structure as a factor in urban forest development, Urban Ecology, 9(3), 245-266.

McEwan, R. W., Dyer, J. M., \& Pederson, N. (2011), Multiple interacting ecosystem drivers: toward an encompassing hypothesis of oak forest dynamics across eastern North America, Ecography, 34(2), 244-256.

McGarigal, K. (2013), Landscape Pattern Metrics, Encyclopedia of Environmetrics. DOI: 10.1002/9780470057339.

McHenry-County-Conservation-District (2009), The Oaks of McHenry County, McHenry County Conservation District, Woodstock, IL, USA pp. 91.

McShea, W. J., \& Healy, W. M. (2002), Oak forest ecosystems: ecology and management for wildlife, Johns Hopkins University Press, Baltimore, MD, USA.

Medley, K. E., McDonnell, M. J., \& Pickett, S. T. (1995), Forest-Landscape Structure along an Urban-To-Rural Gradient, The Professional Geographer, 47(2), 159-168.

Miller, M. D. (2012), The impacts of Atlanta's urban sprawl on forest cover and fragmentation, Applied Geography, 34 171-179.

Nowak, D. J. (1993), Historical vegetation change in Oakland and its implications for urban forest management, Journal of Arboriculture, 19(5), 313-319. 
Nowak, D. J., Hoehn III, R. E., Bodine, A. R., Crane, D. E., Dwyer, J. F., Bonnewell, V., \& Watson, G. (2013), Urban trees and forests of the Chicago region, USDA Forest Service Northern Research Station, Resource Bulletin NRS-84, Newtown Square, PA, USA, pp. 106.

Nowak, D. J., Rowntree, R. A., McPherson, E. G., Sisinni, S. M., Kerkmann, E. R., \& Stevens, J. C. (1996), Measuring and analyzing urban tree cover, Landscape and Urban Planning, 36(1), 49-57.

Nowak, D. J., \& Walton, J. T. (2005), Projected urban growth (2000-2050) and its estimated impact on the US forest resource, Journal of Forestry, 103(8), 383-389.

Pickett, S. T., Cadenasso, M., Grove, J., Nilon, C., Pouyat, R., Zipperer, W., \& Costanza, R. (2008), Urban ecological systems: linking terrestrial ecological, physical, and socioeconomic components of metropolitan areas, in: Urban Ecology (J. M. Marzluff, et. al. , ed.), Springer, New York, NY, USA, pp. 99-122.

Qian, Y., Zhou, W., Yu, W., \& Pickett, S. T. (2015), Quantifying spatiotemporal pattern of urban greenspace: new insights from high resolution data, Landscape Ecology, 30(7), 1-9.

Radeloff, V. C., Hammer, R. B., \& Stewart, S. I. (2005), Rural and suburban sprawl in the US Midwest from 1940 to 2000 and its relation to forest fragmentation, Conservation Biology, 19(3), 793-805.

Rempel, R. S., Kaukinen, D., \& Carr, A. P. (2012), Patch analyst and patch grid, Ontario Ministry of Natural Resources. Centre for Northern Forest Ecosystem Research, Thunder Bay, Ontario.

Rhemtulla, J. M., Mladenoff, D. J., \& Clayton, M. K. (2009), Legacies of historical land use on regional forest composition and structure in Wisconsin, USA (mid-1800s-1930s-2000s), Ecological Applications, 19(4), 1061-1078.

Riitters, K. H., Wickham, J. D., O'Neill, R. V., Jones, K. B., Smith, E. R., Coulston, J. W., Wade, T. G., \& Smith, J. H. (2002), Fragmentation of continental United States forests, Ecosystems, 5(8), 815-822.

Rissman, A. R., Lozier, L., Comendant, T., Kareiva, P., Kiesecker, J. M., Shaw, M. R., \& Merenlender, A. M. (2007), Conservation easements: biodiversity protection and private use, Conservation Biology, 21(3), 709-718.

Robinson, G. R., \& Handel, S. N. (2000), Directing spatial patterns of recruitment during an experimental urban woodland reclamation, Ecological Applications, 10(1), 174-188.

Rodewald, P. G., \& Matthews, S. N. (2005), Landbird use of riparian and upland forest stopover habitats in an urban landscape, The Condor, 107(2), 259-268.

Rudd, H., Vala, J., \& Schaefer, V. (2002), Importance of backyard habitat in a comprehensive biodiversity conservation strategy: a connectivity analysis of urban green spaces, Restoration Ecology, 10(2), 368-375.

Samson, F., \& Knopf, F. (1994), Prairie conservation in North America, BioScience, 44(6), 418421.

Sanders, R. A. (1984), Some determinants of urban forest structure, Urban Ecology, 8(1), 13-27.

SAS-Institute-Inc. (2015), SAS v. 9.4, SAS Institute Inc., Durham, NC, US.

Schleeweis, K., Goward, S. N., Huang, C., Masek, J. G., Moisen, G., Kennedy, R. E., \& Thomas, N. E. (2013), Regional dynamics of forest canopy change and underlying causal processes in the contiguous US, Journal of Geophysical Research: Biogeosciences, 118(3), 1035-1053. 
Schulte, L. A., \& Mladenoff, D. J. (2001), The original US public land survey records: their use and limitations in reconstructing presettlement vegetation, Journal of Forestry, 99(10), 510.

Sharpe, D. M., Stearns, F., Leitner, L. A., \& Dorney, J. R. (1986), Fate of natural vegetation during urban development of rural landscapes in southeastern Wisconsin, Urban Ecology, 9(3-4), 267-287.

Smith, C. (2009), The plan of Chicago: Daniel Burnham and the remaking of the American city, University of Chicago Press, Chicago, IL, USA, pp. 202.

SYSTAT-Software-Inc. (2015), Sigmaplot v. 13, SYSTAT Software Inc., San Jose, CA.

Transeau, E. N. (1935), The prairie peninsula, Ecology, 16(3), 423-437.

US-Census-Bureau (2010), US Census Bureau Data, www.census.gov.

Ward, K., Kromroy, K., \& Juzwik, J. (2007), Transformation of the oak forest spatial structure in the Minneapolis/St. Paul metropolitan area, Minnesota, USA over 7 years, Landscape and Urban Planning, 81(1), 27-33.

Willman, H. B. (1971), Summary of the geology of the Chicago area., in: Circular 460. , Illinois State Geological Survey, Urbana, IL, USA.

Wood, E. M., Pidgeon, A. M., Radeloff, V. C., Helmers, D., Culbert, P. D., Keuler, N. S., \& Flather, C. H. (2014), Housing development erodes avian community structure in US protected areas, Ecological Applications, 24(6), 1445-1462.

Zhou, W., Huang, G., Pickett, S. T., \& Cadenasso, M. (2011), 90 years of forest cover change in an urbanizing watershed: spatial and temporal dynamics, Landscape Ecology, 26(5), 645659.

Zipperer, W. C. (2002), Species composition and structure of regenerated and remnant forest patches within an urban landscape, Urban Ecosystems, 6(4), 271-290. 


\section{List of Tables}

Table 1. Characteristics of regional forest ecosystems in the three time periods analyzed and for protected lands and three different levels of parcel aggregation in the modern landscape.

Table 2. Counties in the Chicago Wilderness region with characteristics of human population and forest ecosystems.

Table 3. Counties in the Chicago Wilderness region with forest ecosystem landscape metrics and changes from 1939 to 2010 in landscape metrics.

Table 4. Multiple linear regression models of forest ecosystem retention at the census tract scale and multiple logistic regression models of forest ecosystem retention at the census tract scale. Only five most highly supported models are included, full model lists included in Tables B1 and B2 in Supplementary Material.

Table 5. Characteristics of Urban Tree Census plots (Nowak et al., 2013) in relation to presettlement land cover and timing of conversion of original forest to urban or agricultural land use. 


\section{Tables}

Table 1. Characteristics of regional forest ecosystems in the three time periods analyzed and for protected lands and three different levels of parcel aggregation in the modern landscape.

\begin{tabular}{llllrrrrr}
\hline & $\begin{array}{l}\text { Total } \\
\text { area } \\
\text { (ha) }\end{array}$ & $\begin{array}{l}\text { Percent } \\
\text { of PLS } \\
\text { Area }\end{array}$ & $\begin{array}{l}\text { Core } \\
\text { Area } \\
(\text { ha })^{\&}\end{array}$ & $\begin{array}{l}\text { Parcels } \\
\text { >50ha }\end{array}$ & $\begin{array}{l}\text { Parcels } \\
\text { >100ha }\end{array}$ & $\begin{array}{l}\text { Parcels } \\
\text { >200ha }\end{array}$ & $\begin{array}{l}\text { Parcels } \\
\text { >400ha }\end{array}$ & $\begin{array}{l}\text { Core } \\
\text { Parcels } \\
\text { >10 ha }\end{array}$ \\
\hline PLS* & 419470 & -- & 185055 & 89 & 73 & 48 & 145 & 411 \\
1939 & 113254 & 27.0 & 14096 & 216 & 79 & 27 & 1 & 322 \\
2010 & 69958 & 16.7 & 5934 & 121 & 46 & 6 & 0 & 141 \\
2010 Protected & 21083 & 5.0 & 2451 & 49 & 17 & 1 & 0 & 67 \\
2010 Agg 100m & 78558 & 18.7 & 8382 & 117 & 59 & 27 & 22 & 175 \\
2010 Agg 200m & 97375 & 23.2 & 20134 & 150 & 91 & 42 & 33 & 408 \\
\hline
\end{tabular}

* PLS and 1939/2010 layers were developed using different data sources (PLS notes vs. aerial imagery) and methodologies and thus comparisons should not be made quantitatively and interpreted with caution ${ }^{\&}$ Area $\geq 100 \mathrm{~m}$ from patch edge 
Table 2. Counties in the Chicago region with characteristics of human population and forest ecosystems.

\begin{tabular}{|c|c|c|c|c|c|c|c|c|c|c|c|}
\hline Counties & $\begin{array}{l}\text { Density } \\
(\text { per } \\
\left.\mathrm{km}^{2}\right)\end{array}$ & $\begin{array}{l}\text { Percent } \\
\text { urban } \\
\text { population }^{\wedge}\end{array}$ & $\begin{array}{l}\text { Percent } \\
\text { population } \\
\text { change } \\
\text { (1940 to } \\
\text { current) }\end{array}$ & Foreste & osystem ar & $e a(h a)$ & 1939 & nt cons & $\begin{array}{l}2010 \\
v s \\
1939 \\
\end{array}$ & $\begin{array}{l}\text { Percent } \\
\text { protected }\end{array}$ & $\begin{array}{l}\text { Total } \\
\text { area } \\
(\text { ha })^{*}\end{array}$ \\
\hline Boone & 74.5 & 80.6 & 71.9 & 17904 & 2522 & 1586 & 14.1 & 8.9 & 62.9 & 9.4 & 57223 \\
\hline Cook & 2121.7 & 99.9 & 21.8 & 50396 & 14092 & 8963 & 28.0 & 17.8 & 63.6 & 80.0 & 244857 \\
\hline DeKalb & 64.3 & 79.7 & 67.3 & 14325 & 3778 & 2430 & 26.4 & 17.0 & 64.3 & 11.6 & 159322 \\
\hline DuPage & 1081.0 & 99.9 & 88.7 & 13792 & 6069 & 2766 & 44.0 & 20.1 & 45.6 & 57.6 & 86116 \\
\hline Grundy & 46.3 & 75.6 & 63.3 & 11723 & 4977 & 3667 & 42.5 & 31.3 & 73.7 & 6.4 & 110220 \\
\hline Iroquois & 10.3 & 28.3 & -9.3 & 16386 & 4343 & 3028 & 26.5 & 18.5 & 69.7 & 8.1 & 119861 \\
\hline Kane & 382.5 & 96.4 & 74.7 & 50390 & 10445 & 5758 & 20.7 & 11.4 & 55.1 & 25.1 & 134164 \\
\hline Kankakee & 64.7 & 75.5 & 46.3 & 22819 & 8177 & 4984 & 35.8 & 21.8 & 61.0 & 19.9 & 174382 \\
\hline Kendall & 138.3 & 89.6 & 90.3 & 9929 & 4296 & 2942 & 43.3 & 29.6 & 68.5 & 13.4 & 82514 \\
\hline Lake & 612.2 & 98.7 & 82.8 & 70648 & 18803 & 9442 & 26.6 & 13.4 & 50.2 & 34.8 & 120397 \\
\hline LaSalle & 38.8 & 69.8 & 14.2 & 18382 & 9245 & 7350 & 50.3 & 40.0 & 79.5 & 8.4 & 116590 \\
\hline Lee & 19.2 & 46.8 & 4.0 & 618 & 71 & 29 & 11.6 & 4.7 & 40.7 & 0 & 6201 \\
\hline McHenry & 197.6 & 90.1 & 87.9 & 70490 & 10886 & 7306 & 15.4 & 10.4 & 67.1 & 15.8 & 156368 \\
\hline Ogle & 27.2 & 52.9 & 44.2 & 1363 & 419 & 305 & 30.7 & 22.4 & 72.9 & 0 & 28995 \\
\hline Will & 312.6 & 96.1 & 83.1 & 39834 & 12072 & 7381 & 30.3 & 18.5 & 61.1 & 38.7 & 217356 \\
\hline Winnebago & 222.1 & 92.1 & 59.0 & 5599 & 1644 & 1152 & 29.4 & 20.6 & 70.1 & 36.3 & 14831 \\
\hline Total/Avg. & 338.3 & 79.5 & 55.6 & 414612 & 111943 & 69148 & 27.0 & 16.7 & 61.8 & 30.1 & 1882220 \\
\hline
\end{tabular}

*Area of portion of county included within the Chicago Wilderness region.

$\wedge$ Based on US Census Bureau definition (US-Census-Bureau, 2010). 
Table 3. Counties in the Chicago region with forest ecosystem landscape metrics and changes from 1939 to 2010 in landscape metrics.

\begin{tabular}{|c|c|c|c|c|c|c|c|c|c|c|}
\hline Counties & $\begin{array}{l}2010 \\
\text { Core } \\
\text { area } \\
(\text { ha })^{\text {\& }}\end{array}$ & $\begin{array}{l}2010 \\
\text { Percent } \\
\text { core } \\
\text { area } \\
\end{array}$ & $\begin{array}{l}2010 \\
\text { Mean } \\
\text { patch } \\
\text { size (ha) }\end{array}$ & $\begin{array}{l}2010 \\
\text { Mean } \\
\text { PAR* }\end{array}$ & $\begin{array}{l}2010 \\
E D^{*} \\
\end{array}$ & $\begin{array}{l}\text { Patch } \\
\text { size } \\
\text { (ha) } \\
\end{array}$ & $\begin{array}{l}\text { five Cha } \\
39-2010\end{array}$ & $E D^{*}$ & $\begin{array}{l}2010 \\
\text { Nearest } \\
\text { neighbor } \\
\text { ratio }\end{array}$ & $\begin{array}{l}\text { Change in } \\
\text { nearest } \\
\text { neighbor } \\
\text { ratio 1939- } \\
2010 \\
\end{array}$ \\
\hline Boone & 35.7 & 32.4 & 82.2 & 63.0 & 1.02 & 21.9 & 10.8 & 18.0 & 0.70 & 0.06 \\
\hline Cook & 1510.1 & 63.9 & 183.8 & 61.7 & 3.75 & 11.8 & 15.6 & 11.6 & 0.39 & 0.06 \\
\hline DeKalb & 150.1 & 39.2 & 125.1 & 63.0 & 1.34 & 19.3 & 7.3 & 17.8 & 0.44 & 0.07 \\
\hline DuPage & 174.5 & 24.2 & 100.5 & 69.6 & 1.71 & 36.8 & 17.4 & -3.0 & 0.57 & 0.12 \\
\hline Grundy & 337.6 & 54.6 & 198.8 & 75.1 & 2.12 & 25.6 & 10.2 & 28.4 & 0.59 & 0.04 \\
\hline Iroquois & 165.8 & 59.4 & 141.6 & 76.3 & 2.14 & 18.8 & 19.3 & 27.4 & 0.53 & 0.04 \\
\hline Kane & 219.4 & 23.8 & 85.7 & 71.2 & 3.97 & 15.6 & 6.9 & 13.0 & 0.76 & 0.12 \\
\hline Kankakee & 392.4 & 24.9 & 144.0 & 69.0 & 2.85 & 35.4 & 17.5 & 31.1 & 0.53 & 0.07 \\
\hline Kendall & 170.5 & 31.9 & 140.3 & 74.9 & 1.82 & 23.0 & 8.9 & 28.8 & 0.62 & 0.08 \\
\hline Lake & 658.5 & 28.7 & 69.0 & 90.7 & 7.82 & 23.5 & 7.1 & 4.8 & 0.85 & 0.11 \\
\hline LaSalle & 961.8 & 62.2 & 289.1 & 67.4 & 3.48 & 30.6 & 10.5 & 32.9 & 0.53 & 0.02 \\
\hline Lee & 0.0 & 0.0 & 40.8 & 81.2 & 0.03 & 33.9 & 24.7 & -4.4 & 0.60 & 0.07 \\
\hline McHenry & 313.3 & 37.7 & 56.6 & 94.4 & 4.81 & 36.1 & 16.1 & 30.8 & 0.73 & 0.08 \\
\hline Ogle & 13.0 & 27.9 & 120.4 & 70.0 & 0.18 & 10.5 & 5.2 & 31.8 & 0.38 & 0.19 \\
\hline Will & 715.2 & 44.4 & 121.0 & 76.0 & 4.53 & 28.0 & 16.0 & 20.2 & 0.44 & 0.04 \\
\hline Winnebago & 105.1 & 46.6 & 166.2 & 67.5 & 0.61 & 16.9 & 9.6 & 24.6 & 0.64 & 0.01 \\
\hline Total/Avg. & 5923.0 & 40.1 & 129.1 & 73.2 & 2.60 & 24.2 & 12.7 & 19.6 & 0.51 & 0.06 \\
\hline
\end{tabular}

${ }^{\&}$ Area $\geq 100 \mathrm{~m}$ from patch edge

* PAR - perimeter to area ratio, ED - edge density 
Table 4. Multiple linear and logistic regression models of forest ecosystem retention at the census tract scale and pixel scale. Only five most highly supported models are included, full model lists included in Table B1 and B2 in Supplementary Material.

\begin{tabular}{lrrrr}
\hline Model & Parameters & AIC & \multicolumn{1}{c}{$\Delta$ AIC } & $w_{i}$ \\
\hline Linear regression on census tracts & & & & \\
Impervious_surface Stream_distance* & 4 & -1124.7 & 0 & 0.81 \\
Impervious_surface Stream_distance Median_income & 5 & -1121.4 & 3.3 & 0.16 \\
Impervious_surface Household_density Stream_distance Median_income & 6 & -1117.2 & 7.5 & 0.02 \\
Impervious_surface Household_density Stream_distance & 5 & -1116 & 8.7 & 0.01 \\
Impervious_surface & 3 & -1079 & 45.7 & 0.00 \\
Logistic regression on pixels & & & & \\
Impervious_surface Household_density Stream_distance Land_use & 6 & 2761.7 & 0.0 & 0.63 \\
Impervious_surface Stream_distance Land_use & 5 & 2762.8 & 1.1 & 0.36 \\
Impervious_surface Household_density Land_use & 5 & 2773.4 & 11.8 & 0.00 \\
Impervious_surface Land_use & 4 & 2774.7 & 13.0 & 0.00 \\
Household_density Land_use & 4 & 2949.5 & 187.9 & 0.00 \\
\hline
\end{tabular}

$*$ Regression coefficients: Forest Conversion $\%=0.4657+0.0038 *$ Impervious surface $\%+0.039 *$ distance to stream $(\mathrm{km})$ 
Table 5. Characteristics of Urban Tree Census plots (Nowak et al., 2013) in relation to presettlement land cover and timing of conversion of original forest to urban or agricultural land use.

\begin{tabular}{lrrrrrrrr}
\hline & $\begin{array}{l}\text { Canopy } \\
\text { cover } \\
\text { Category }\end{array}$ & $\begin{array}{l}\text { Total } \\
\text { BA* } \\
\left.\mathrm{ha}^{-1}\right)\end{array}$ & $\begin{array}{l}\text { Snag BA } \\
\left(\mathrm{m}^{2} \mathrm{ha}^{-1}\right)\end{array}$ & $\begin{array}{l}\text { Oak } \\
\text { dominance }\end{array}$ & $\begin{array}{l}\text { Non-native } \\
\text { dominance }\end{array}$ & $\begin{array}{l}\text { Maximum } \\
\text { DBH } \\
(\mathrm{cm})\end{array}$ & $\begin{array}{l}\text { Maximum } \\
\text { height }(\mathrm{m})\end{array}$ \\
\hline Non-forest in PLS & 342 & 14.6 & 8.6 & 0.21 & 5.0 & 53.5 & 35.9 & 12.3 \\
Converted pre-1939 & 158 & 35.0 & 16.1 & 0.03 & 18.2 & 41.4 & 40.2 & 13.9 \\
Converted post-1939 & 20 & 62.7 & 26.3 & 0.38 & 45.7 & 28.6 & 59.3 & 17.6 \\
Remnant 2010 & 44 & 73.7 & 29.5 & 0.72 & 51.2 & 11.9 & 65.7 & 23.2 \\
Total/Average & $\mathbf{5 6 4}$ & $\mathbf{2 2 . 6}$ & $\mathbf{1 1 . 5}$ & $\mathbf{0 . 3 4}$ & $\mathbf{1 0 . 2}$ & $\mathbf{3 3 . 9}$ & $\mathbf{5 0 . 3}$ & $\mathbf{1 6 . 7}$ \\
\hline F & -- & 58.55 & 42.34 & 2.78 & 61.59 & 2.63 & 22.02 & 41.47 \\
p & -- & $<0.001$ & $<0.001$ & 0.04 & $<0.001$ & 0.05 & $<0.001$ & $<0.001$ \\
\hline
\end{tabular}

* BA - basal area, DBH - diameter at breast height $(1.37 \mathrm{~m}$ above ground $)$ 


\section{List of Appendices}

\section{Appendix A}

Table A1. Correlation of county-level socio-economic conditions with forest ecosystem retention and patch characteristics.

Table A2. Area (ha) of protected forest ecosystems by county and ownership type

\section{Appendix B}

Table B1. Multiple linear regression models of forest ecosystem retention at the census tract scale.

Table B2. Multiple logistic regression models of forest ecosystem retention at the census tract scale.

\section{Appendix C}

Figure $\mathrm{C} 1$. Retention of forest ecosystem by municipality in relation to municipal incorporation date. Only municipalities with $\geq 1000$ ha of original forest ecosystem were included in the analysis.

Figure C2. Frequency distribution of parcel sizes for 1939 and 2010 analysis periods. 


\section{Acknowledgements}

Funding for this research was provided by USDA Forest Service State and Private Forestry in a grant (FY12-IL-146) to the Chicago Wilderness Trust. Significant contributions to grant writing, administration and coordination were made by the Chicago Wilderness Oak Recovery Working Group - especially Lindsay Darling, Jim Anderson, Chris Mulvaney, Ed Collins, Suzanne MalecMcKenna, and Melinda Pruett-Jones and the Chicago Region Trees Initiative - especially Lydia Scott. Corinne Erickson assisted in georectifying 1939 aerial images. 


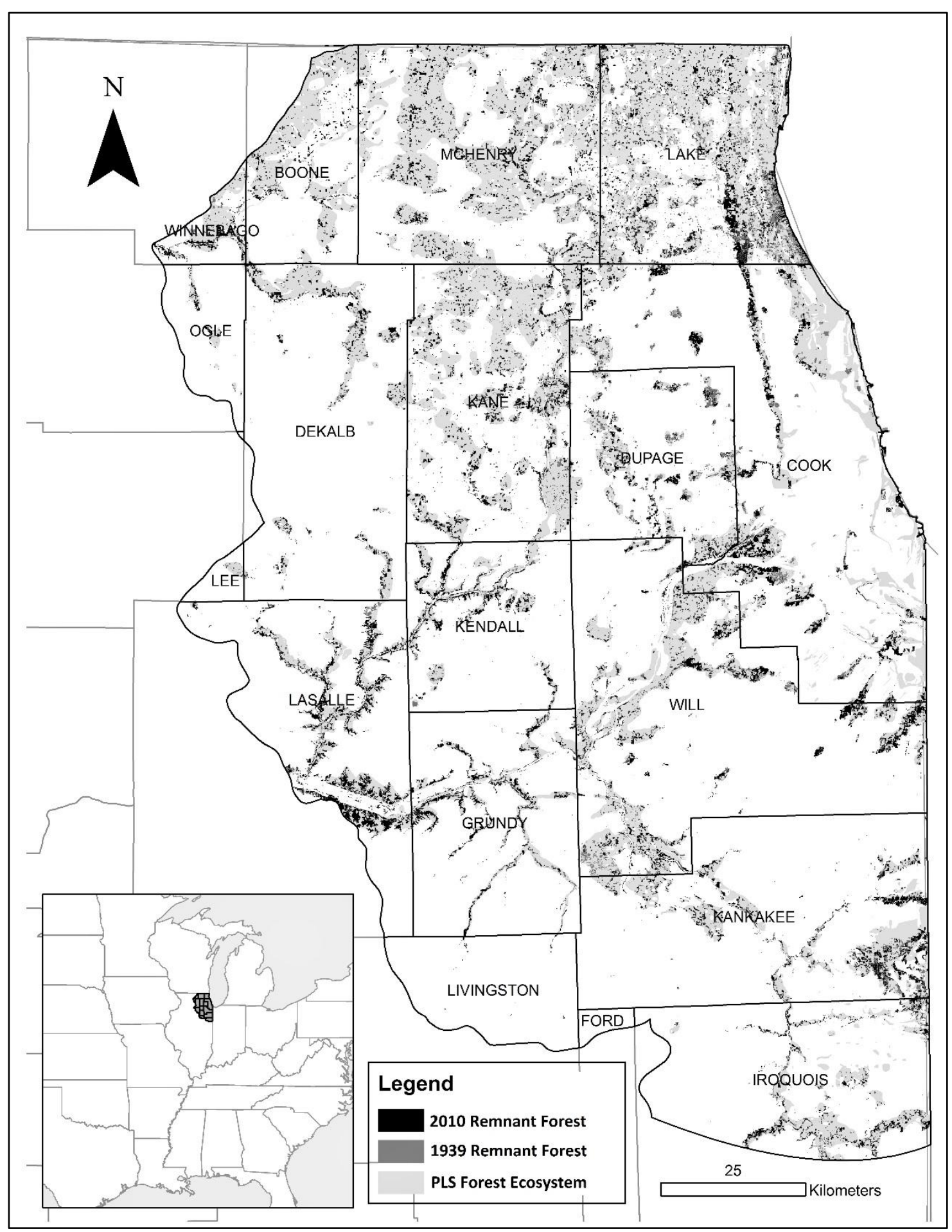

Figure 1. Map of Chicago region illustrating the extent of forest ecosystems in three time periods - 1830's based on Public Land Surveys (PLS), and 1939 and 2010 based on aerial image analysis. Inset illustrates position of Chicago metropolitan region within eastern North America. 

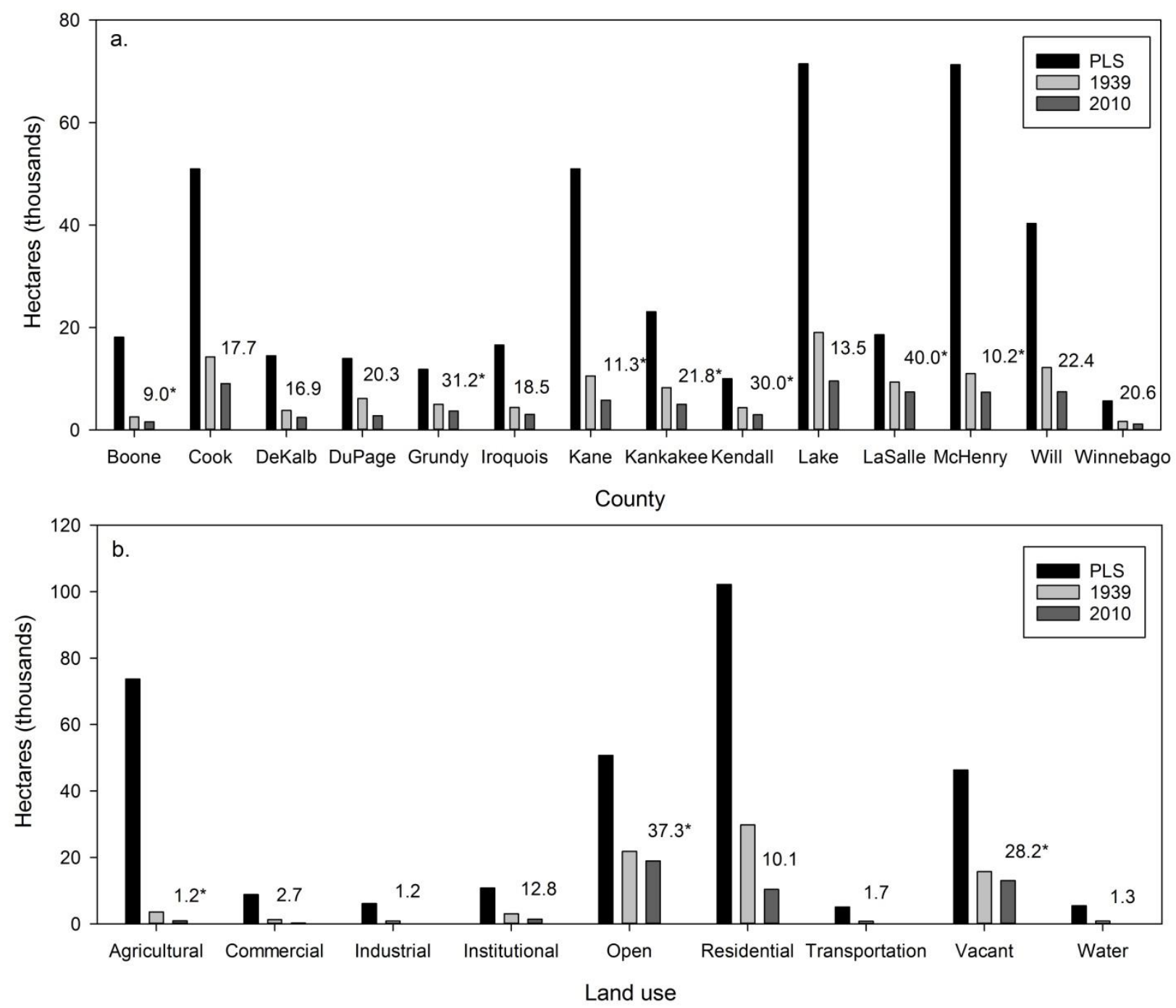

Figure 2. Forest ecosystem area in three time periods (PLS Era-1830's, 1939, and 2010) by a) county and b) modern land-use type. Numbers indicate percent of original PLS forest ecosystem that remained in 2010 in each category and * indicates that standardized residual from contingency table analysis was significant $(\geq 2$ or $\leq-2)$. 

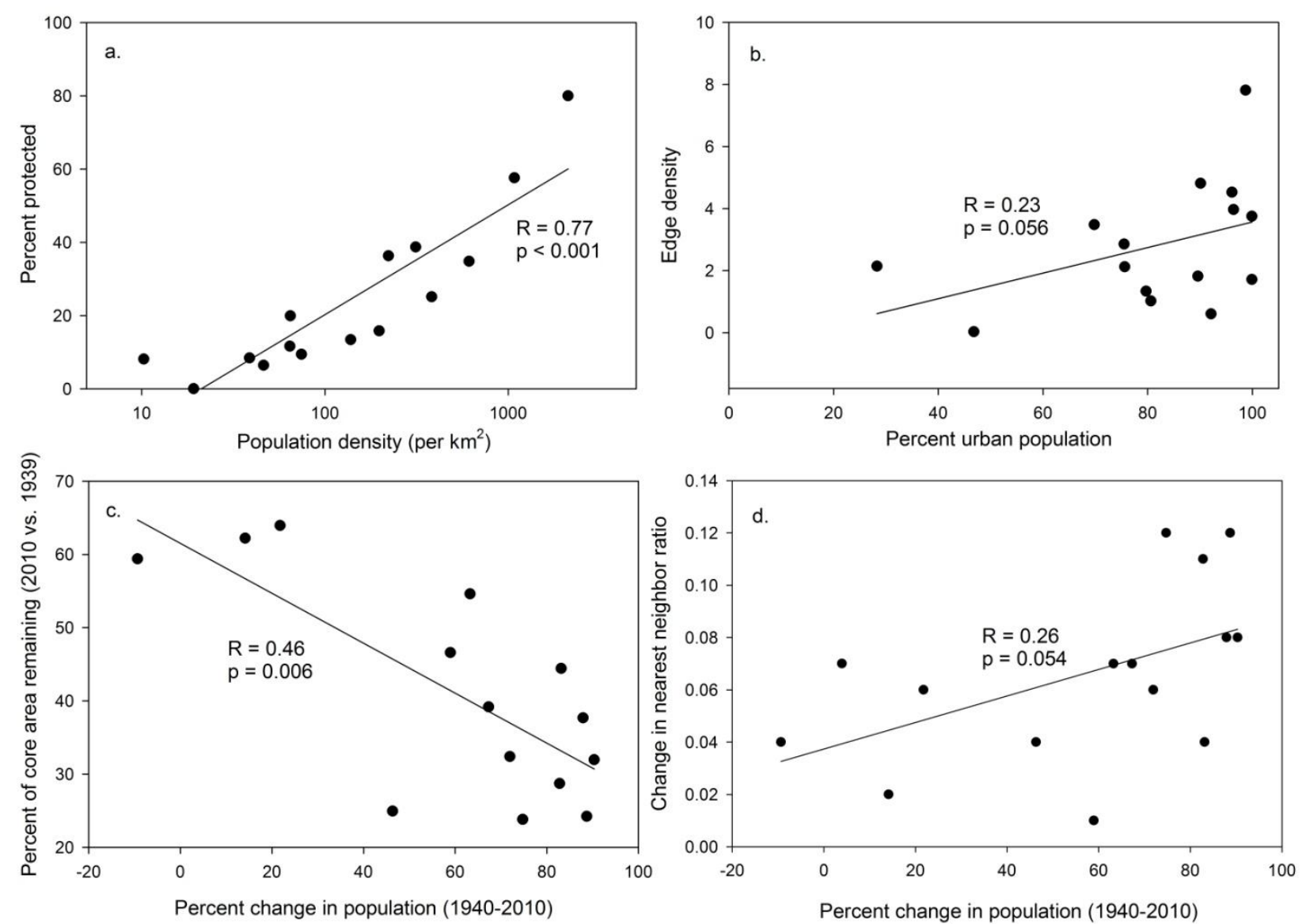

Figure 3. Relationships between county-level population characteristics, measures of protected status, and fragmentation. 


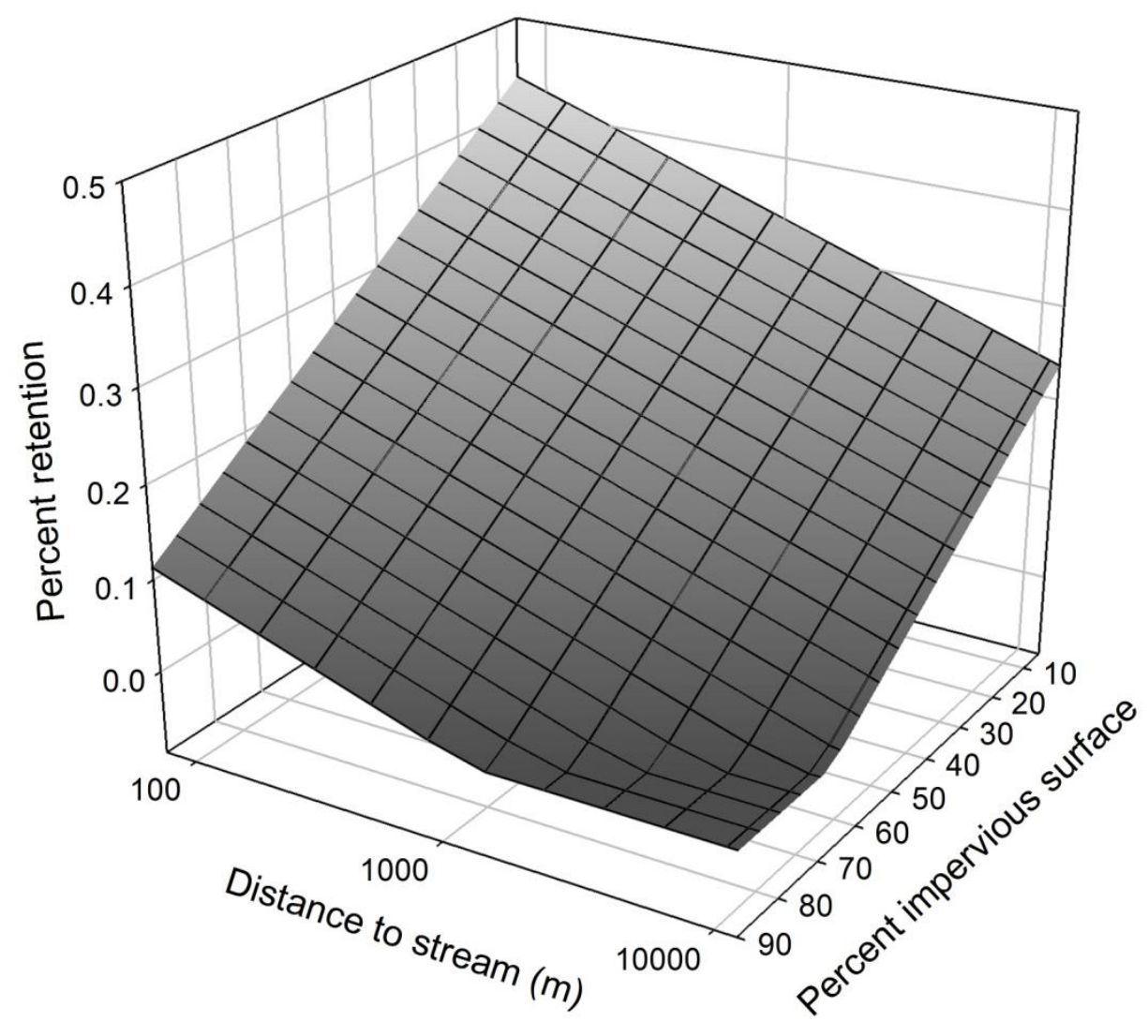

Figure 4. Multiple linear regression model of forest ecosystem retention at the census tract level as a function of distance to stream (note logarithmic scale) and percent impervious surface. 


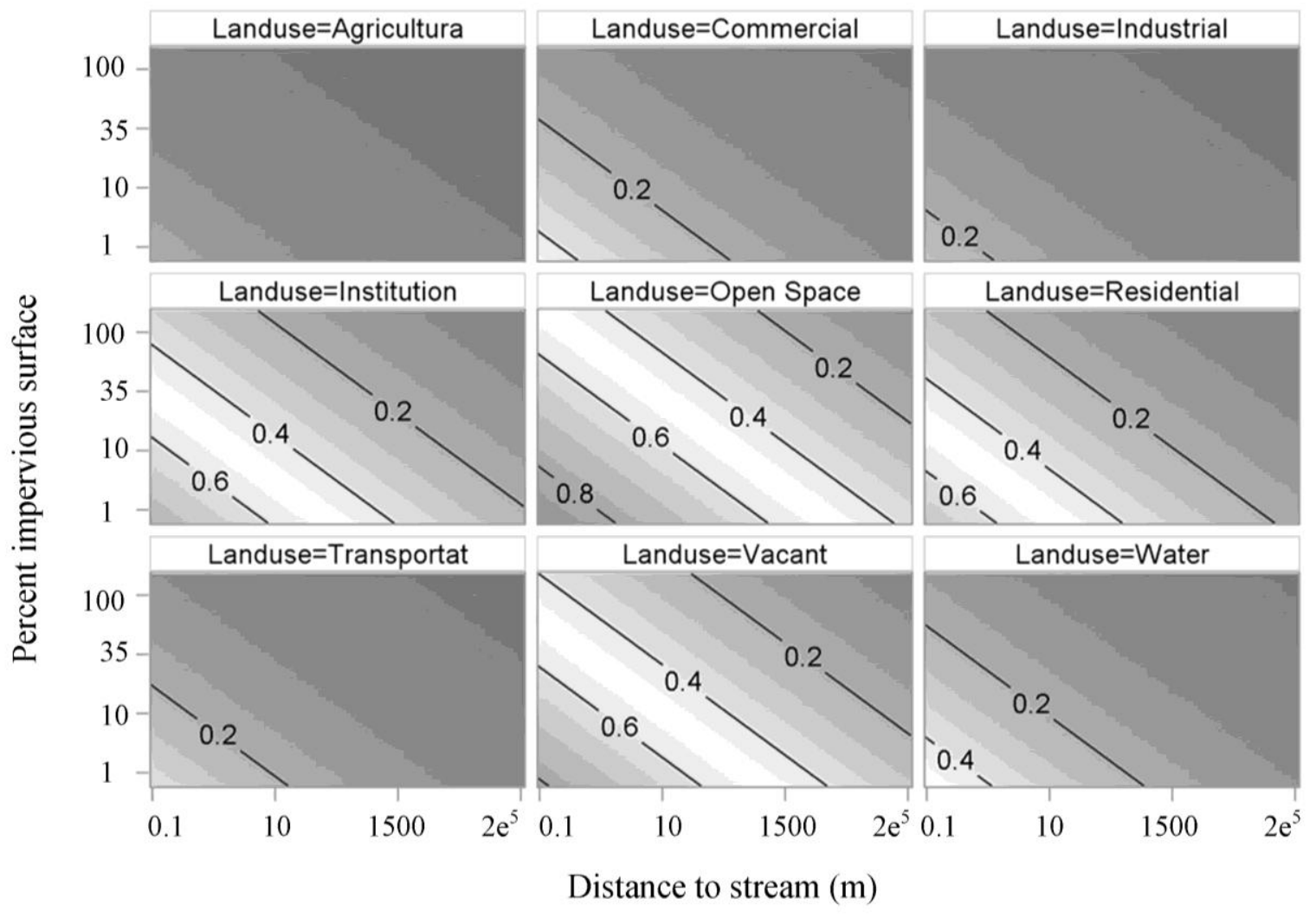

Figure 5. Probability of forest ecosystem retention as a function of distance to stream and percent impervious surface by modern land use category based on multiple logistic regression analysis of individual 1ha pixels in original PLS forest ecosystem layer. For Agricultural land use (top left panel) probability was $<0.2$ for all values of stream distance and impervious surface. 